\title{
Non-penetrance and late appearance of polyps in families with familial adenomatous polyposis
}

D G R Evans, S P Guy, N Thakker, J G Armstrong, C Dodd, D R Davies, C Babbs, T Clancy, T Warnes, P Sloan, T V Taylor, $R$ Harris

Department of Medical Genetics, St Mary's

Hospital, Manchester

D G R Evans

S P Guy

N Thakker

J G Armstrong

T Clancy

D R Davies

$R$ Harris

Department of

Gastroenterology,

Manchester Royal

Infirmary

C Babbs

D R Davies

$T$ Warnes

Department of Surgery,

Manchester Royal

Infirmary

T V Taylor

Department of

Ophthalmology,

Manchester Royal Eye

Hospital

C Dodds

Department of Oral

Medicine, Manchester

University Dental School

N Thakker

P Sloan

Correspondence to:

Dr D G R Evans, Department

of Medical Genetics, St Mary's

Hospital, Manchester

M130JH.

Accepted for publication

2 February 1993

\section{Abstract}

One case of non-penetrance of the familial adenomatous polyposis (FAP) gene at 59 years of age and late onset of polyps on endoscopy and biopsy in this and two other families is described. Screening protocols should include dental screening as well as indirect ophthalmoscopy and endoscopy to detect minimal manifestations of the gene. In the absence of a specific DNA predictive test, bowel screening should continue well beyond $\mathbf{3 0}$ years of age.

(Gut 1993; 34: 1389-1393)

Familial adenomatous polyposis (FAP) has only recently been shown by clinical and molecular studies to encompass the two conditions formerly known as Gardner syndrome and polyposis coli. ${ }^{12}$ It has been generally accepted that adenomatous polyps develop in the second and third decade with most affected untreated subjects developing a colorectal carcinoma by the age of 40 years. ${ }^{3}$ Indeed a recent assessment of 137 at risk subjects using sigmoidoscopy predicted that all those affected would develop rectal polyps by 34 years of age. ${ }^{4}$ Our experience with over 30 families in the North West of England has led us to doubt these assessments for expression of both polyps and carcinoma. We present three families with late onset of polyps and an apparently non-penetrant individual aged 59 years.

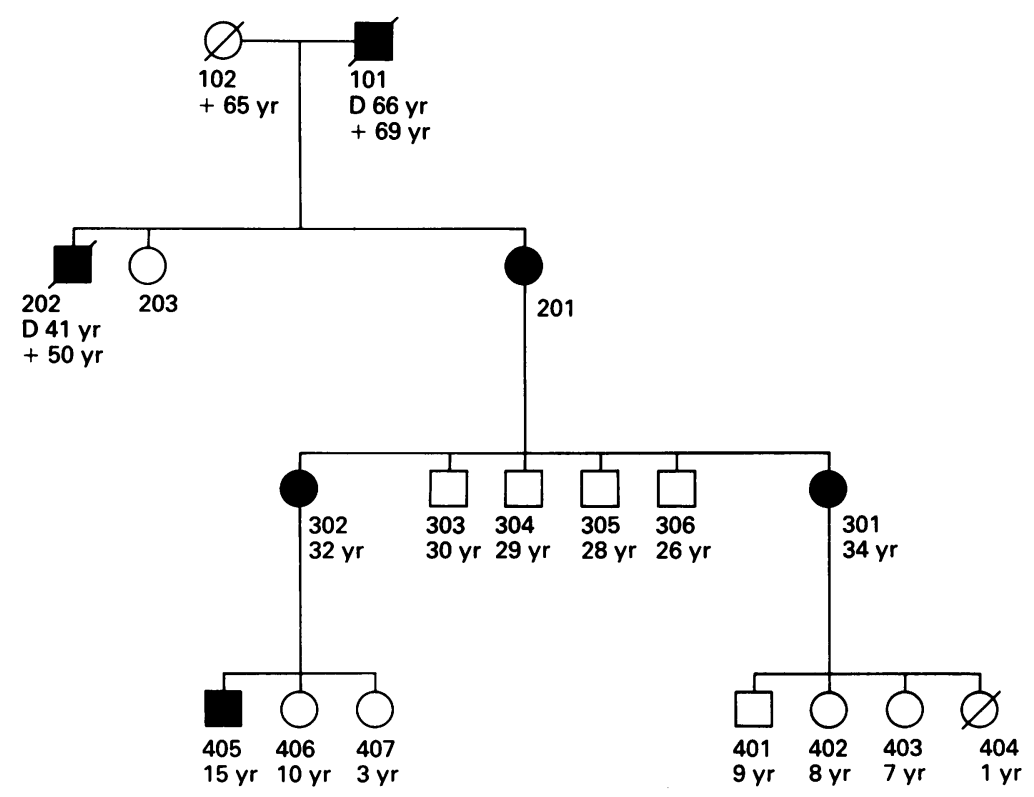

Figure 1: Family pedigree of family 1.

\section{Case reports}

FAMILY 1

Figure 1 represents this family.

Patient 101 - presented at the age of 66 years with intermittent diarrhoea. Barium enema showed multiple polyps in the rectum and he had total panproctocolectomy with ileostomy. There were over 100 adenomatous polyps present throughout the specimen, but only two showed in situ foci and there was no evidence of invasive carcinoma. The patient was noted to have multiple skin cysts (histology showed an epidermoid origin) and osteomata of the skull. He died at the age of 69 of an unrelated squamous cell carcinoma of the bronchus.

Patient 202 - presented aged 41 years with a rectal adenocarcinoma associated with over 100 adenomatous polyps. He had a proctectomy and partial colectomy, but unfortunately died aged 50 years from multiple new carcinomata in the retained ascending colon. He was also noted to have cysts and skull osteomata.

Patient 201 - submitted to screening aged 34 years in view of familial history. Barium enema suggested the presence of polyps, but sigmoidoscopy to $22 \mathrm{~cm}$ was normal. An incidental asymptomatic breast adenocarcinoma was discovered and she had a right simple mastectomy. The patient was lost to follow up two years later until her daughter (301) presented to the oral medicine department. Patient 201 is now 54 years of age and has had epidermoid cysts removed as well as having a large jaw osteoma. She remains asymptomatic from her bowel and a recent colonoscopy showed only four small polyps in the rectosigmoid region, with no further polyps to the caecum.

Patient 301 - presented to the oral medicine department aged 32 years. Noted to have typical jaw features of Gardner syndrome, with skin cysts and in view of family history was referred for colonoscopy. Examination round to the caecum showed no abnormality and biopsy specimens showed normal colonic mucosa.

Patient 302 - only two small polyps, in the rectum but hundreds of adenomatous polyps $>0.5 \mathrm{~cm}$ diameter from the rectum to caecum on colonoscopy aged 32 years. Also has multiple osteomata and skin cysts.

Patient 405 - large jaw osteoma noted at 15 years with colonoscopy showing areas of microadenomata on biopsy.

\section{FAMILY 2}

Figure 2 shows this family.

Patients 101 and 102 died at the ages of 72 and 70 years with no known features of FAP and no cancer. 


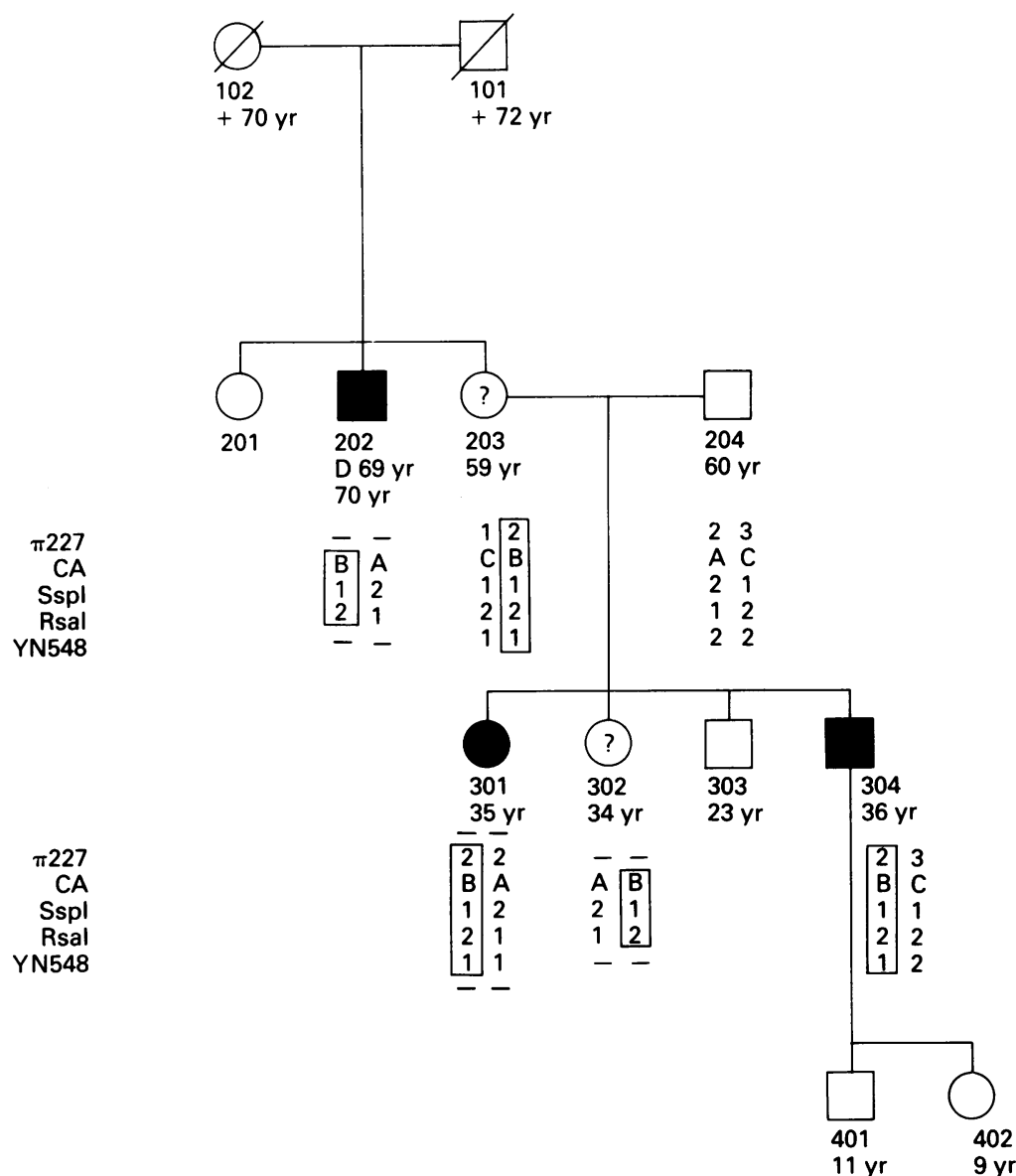

Figure 2: Pedigree of family 2 showing haplotypes of the polymorphisms detected with flanking probes $\pi 227$ and $Y N 5 \cdot 48$, the CA repeat marker, and the intragenic markers RsaI and SspI. For each probe, 1 denotes the larger allele and 2 the smaller. With the $C A$ repeat marker the alleles are labelled $A$ to $C$. Affected members with polyps are blacked in and those thought to be affected have $a$ ? The order of alleles in case 202 is assumed as phase cannot be derived from parental haplotypes. The affected chromosomal region is represented by outline in a rectangle. Patients 301 and 304 who both have proved polyps have inherited the same chromosome from their mother patient 203 and different chromosomes from their father. Patient 302 who has osteomas, but no polyps has also inherited the affected chromosome. Risks of there being recombinational events within the APC gene to negate these results are $<0 \cdot 1 \%$.

Patient 202 - no problems until presented aged 69 years with rectal bleeding. Colonoscopy showed over 100 adenomatous polyps, but no carcinoma was found on removal of the colon and rectum.

Patient 203 - currently 59 years. Caecum normal on colonoscopy examination at 58 years with two biopsies showing normal mucosa. No skin cysts or jaw osteomata on orthopantograms. In the six months before the recent normal colonoscopy, she had a series of investigations including barium enemas, sigmoidoscopy, and colonoscopy with results which were to some degree conflicting. This was partly influenced by the recognition that she must be an obligate gene carrier as her brother (202), daughter (301), and son (304) were all known to be affected.

Patient 204 - normal sigmoidoscopy aged 60 years. No cysts, osteomata, or retinal pigmentary change.

Patient 301 - presented with bloody diarrhoea aged 30 years. Ileorectal anastamosis for multiple polyps.

Patient 302 - normal colonoscopy and several random biopsies showing normal histology aged 34 years, but orthopantograms highly suggestive of FAP with multiple osteomata.

Patient 304 - over 100 adenomatous polyps present on first screen aged 35 years. Awaiting surgery.

FAMILY 3

Figure 3 shows this family.

Patients 102, 205, 206, 304, and 305 died from bowel cancer associated with multiple polyps. Patients 302 and 303 died from myocardial infarctions but were also known to be affected with polyps found on screening in their late $30 \mathrm{~s}$ and both having later bowel resections.

Patient 201 - died aged 74 years from a cerebrovascular accident. No known bowel symptoms, but was never investigated.

Patient 301 - barium enema and sigmoidoscopy were normal at 35 years. She did not return for screening until developed bowel symptoms aged 53 years. Colonoscopy showed over 100 adenomatous polyps and she had a colectomy and ileorectal anastamosis. No carcinoma was found in the specimen. She was also seen to have multiple areas of retinal pigmentary change.

Patient 402 - adenomatous polyps found on the first screening aged 21 years. Colectomy and ileorectal anastamosis in the same year.

\section{MOLECULAR ANALYSIS}

Blood samples were collected from all available family members and DNA extracted from the leucocytes using an Applied Biosystems Model 340 DNA Extractor. Aliquots (equivalent to $10 \mathrm{ug}$ ) of DNA were digested with the appropriate restriction endonuclease according to manufacturers instructions. Samples were electrophoresed on $0.8 \%$ agarose gels and the size fractionated products transferred to nylon membranes using standard procedures. ${ }^{5}$ Nylon membranes were hybridised to the appropriate ${ }^{32} \mathrm{P}$-dCTP labelled probes (YN5.48 and $\pi 227$ ). After hybridisation, filters were washed to $0 \cdot 2 \times$ SSC and autoradiography carried out at $-70^{\circ} \mathrm{C}$ for two to five days.

Genomic DNA was amplified using the polymerase chain reaction with primers to detect intragenic RsaI and SspI restriction enzyme polymorphic sites and a CA repeat found 30-70 $\mathrm{Kb}$ downstream from the DP2 5 APC gene. ${ }^{6}$ The products of the polymerase chain reaction were loaded on $2 \%$ agarose gels in TRIS borate EDTA in the case of the restriction enzyme polymorphism and on $8 \%$ non-denaturing polyacrylamide for the CA repeat.

Figure 2 shows the results of this analysis. Affected patients 301 and 304 have inherited the same intragenic alleles from their mother, but different ones from their father. In addition, patient 202 has a consistent allelotype with patient 203 and patient 302 who was affected on orthopantograms also seems to have inherited the high risk alleles.

\section{POLYPOSIS REGISTER DATA}

The North Western Regional polyposis register is currently aware of 33 families with proved FAP. These pedigrees contain 123 cases known to have been affected, with 76 currently alive. Thirty four cases have been diagnosed with 


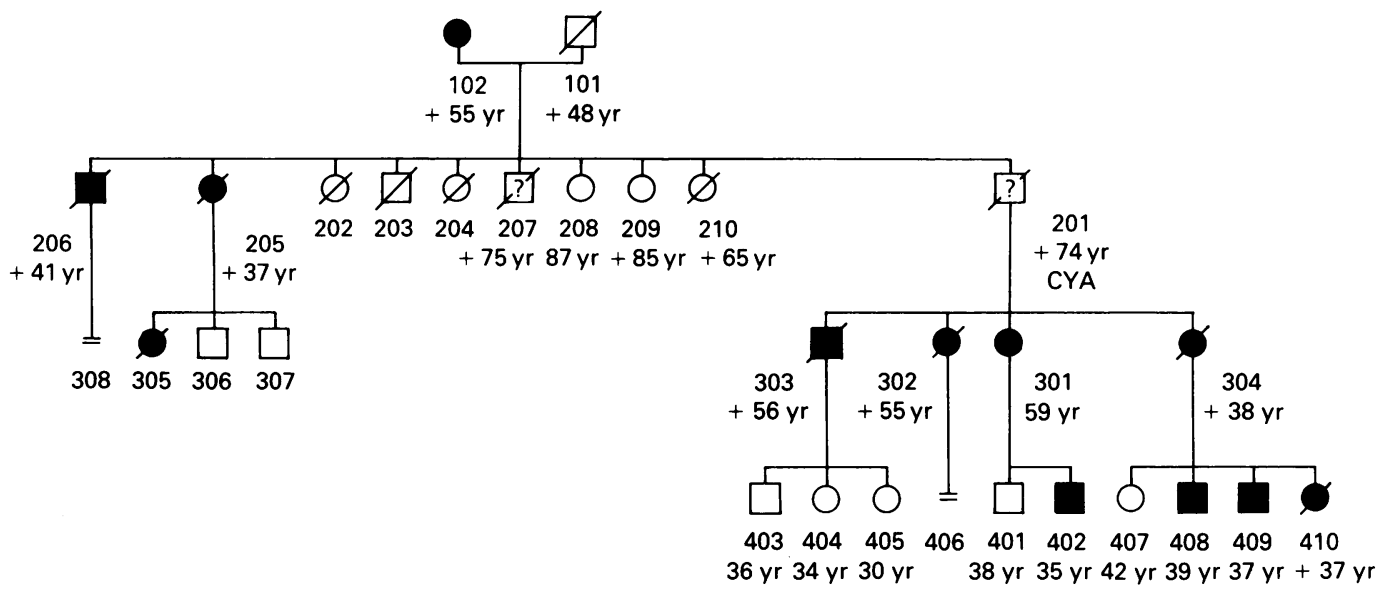

Figure 3: Pedigree of family 3.

asymptomatic polyps at an average age of $21 \cdot 2$ years (range 9-42). Fourteen cases presented symptomatically with polyps at an average of 38.3 years (range 13-69). Seven known affected cases have had a sigmoidoscopy or colonoscopy showing no polyps after 30 years of age $(32,32$, $34,35,39,40$, and 58 years). Two obligate gene carriers have died in their 70s without a bowel cancer or even bowel symptoms and a further case aged 55 years. Seven untreated patients were shown on colonoscopy or colectomy to have no carcinoma after 40 years and two in their late $60 \mathrm{~s}(43,45,52,53,54,66,69$ years). Therefore at least $9 / 120(8 \%)$ patients known to carry the FAP gene did not have a symptomatic bowel cancer after the age of 50 years. Conversely 35 cases have died from bowel cancer at an average of 43.5 years (range 26-69 years). Other related deaths were two from duodenal cancer ( 43 and 48 years), one from a hepatoblastoma (assumed case as offspring of known FAP case aged two years), and a squamous cell carcinoma of the jaw aged 50 years. One further case died from cancer of the bronchus aged 69 years and there were seven other unrelated deaths over the age of 50 years. The earliest presentation with cancer of the bowel in this series was 21 years.

\section{Discussion}

Recent advances in molecular genetics have culminated in the cloning of the APC gene known to cause FAP on chromosome 5.178 Screening of at risk patients with a combination of genetic markers, ophthalmic screening for congenital hypertrophy of the retinal pigment epithelium, and a negative bowel investigation may reduce an initial risk of $50 \%$ to well below $1 \% .^{29}$ Using the incidence curve previously published, ${ }^{4}$ at risk patients with no retinal features of FAP and a negative sigmoidoscopy screen at 34 years would be considered at no risk of having FAP and developing multiple polyps. Clearly although this sample studied 137 patients who had repeated screening, later onset of polyps is likely to occur in some individuals. ${ }^{23}$ From our study we have been able to show that at least $5 \%$ $(6 / 122)$ of patients will not have polyps at 30 years of age on sigmoidoscopy and, as only 36/ 123 in our series were shown to definitely have polyps under 30 years, the real figure may be somewhat higher. It is now generally accepted that FAP is fully penetrant (polyps are present) if the bowel is examined endoscopically. What is not clear is the age at which full penetrance occurs. We have shown that at least one patient is non-penetrant at 59 years of age. Although there have been attempts to assess penetrance in the two phenotypes of Gardner and simple polyposis that have shown low penetrance, ${ }^{10}$ these have relied on the expression of cancer or the extraintestinal features. From the time when endoscopic examination was started, $100 \%$ penetrance has been the rule. Another recent attempt to produce an incidence curve using 126 patients who were screen positive for polyps, determined that $10 \%$ were detected after 40 years of age." There is inherent bias in this study, however, as these cases were not shown to be screen negative, and the age at which polyps were found merely reflects the age at which they were called up for screening. Nevertheless the true incidence curve probably lies somewhere between that of the two studies. ${ }^{411}$

An oft quoted tenet that it is inevitable that someone with FAP will develop a bowel cancer, is also disproved by this study. The clearest example of this is patient 203 from family 2 who has been shown by molecular studies to possess the faulty APC gene. We are not aware of any previously reported case of non-penetrance of any features of FAP at as late an age as 58 years. One would expect there to be at least some degree of microadenoma formation but so far she has only had two areas biopsied. Unfortunately we have not been able to persuade her to have ophthalmic screening, so the presence of congenital hypertrophy of the retinal pigment epithelium is not known. We have been able to show in this population based study that at least $10 \%(12 / 123)$ of subjects over 40 years did not have a bowel cancer, including two cases who were found to have multiple polyps at 66 and 69 years of age, but no carcinoma. Although our study in the North Western Region is by no means complete any bias is likely to be towards finding families with a more severe clinical course.

COUNSELLING ISSUES

Our experience has shown that non-penetrance of the FAP gene and late onset of polyps can have considerable psychosocial implications for the 
particular patient concerned and for their relatives. There can also be a significant impact on family dynamics. These issues need to be borne in mind when counselling such families.

\section{Family 1}

Patient 301 was the first person in this family to be referred for genetic counselling. Subsequently her sister and three of her brothers were seen. The brothers were interested in being screened if we could offer a predictive test based on DNA studies, rather than having bowel examinations while at $50 \%$ risk. This necessitated approaching their parents to ask them to donate blood for DNA extraction. Their mother was known to be at high risk herself given the family history, and we were keen to offer her both counselling and screening for her own benefit. She was very reluctant to take part in any way. This created conflict within the family. Although her children could appreciate her anxieties, they realised the importance of her participation. She did in fact attend clinic eventually, and this allowed a full discussion of the situation. It became clear that her reasons for not wanting to come forward were based largely on feeling guilty about her children being affected or at risk. This was compounded by her belief that her normal examination (aged 34) meant that neither she nor her children were at risk, and she had never discussed the family history with them.

\section{Family 2}

When patient 301 was diagnosed as being affected by FAP, her specialist offered screening to family members identified as being at high risk. Her brother (patient 304) was found to be affected, but neither of their parents had any definite signs of the condition. It then became known that their maternal uncle (patient 202) was also affected. This highlighted their mother as an obligate gene carrier, and she then had the series of investigations outlined earlier. She subsequently attended the genetic counselling clinic, and was very anxious about the situation. She cannot really accept that she 'has the gene' and yet is unaffected. Her experience and state has also caused concern for her children who have had negative bowel examinations and who are awaiting their DNA results.

While other factors may have influenced how these particular families have reacted, it is clear that the unusual genetic picture has caused them problems. This is likely to be the case for other families with a similar pattern of inheritance.

\section{HETEROGENEITY IN FAP}

There is clearly variation in expression of the APC gene within families as can be seen from the three families we have presented in detail. This may, at least in part be because of dietary factors such as non-starch polysaccharides or 'fibre'." There does, however, seem to be a more considerable variation between families. ${ }^{13}$ This may be due to different mutations within the APC gene causing variations from a total absence of gene product through to protein only partially reduced in function. Our study lends credence to the recent report of a family with many affected family members with only two to 40 colonic polyps, who were shown to be linked to the APC locus and are therefore likely to be carrying a mutation of this gene. ${ }^{14}$ Studies to detect the exact mutation or deletion in the APC gene are needed in this and other atypical families before conclusive evidence that it is this locus and not another locus close by such as the MCC gene that is affected. ${ }^{15}$ Although previous reports have suggested, however, a far more virulent course with the Gardner phenotype,$^{13}$ family 1 , which clearly shows this phenotype, has individuals with none and four polyps only at 32 and 54 years respectively.

Currently it is not possible to give $100 \%$ reassurance that an at risk individual has not inherited the faulty APC gene, unless they are shown not to have the family mutation. Mutation studies have until very recently only detected a few defects. Although a new report has been able to identify the gene defect (point mutation, deletion, or insertion) in 53/79 cases, ${ }^{16}$ these tests are unlikely to be widely available for some years and are very labour intensive. This is because there is no real hot spot for mutation, for even though $36 / 79$ (45\%) had detectable defects in exon 15 of the APC gene, this represents one third of the entire gene. Therefore in the families with only one known affected subject, where samples cannot be obtained from enough family members for linkage studies, or in the $20 \%$ or so that remain uninformative with the current probes, no predictive DNA tests are available. This means that well over $50 \%$ of at risk subjects cannot benefit from this technology at present. ${ }^{17}$ As the DNA predictive test is the most accurate predictor of not inheriting the gene, screening beyond 30 years will probably be necessary in about $50 \%$ of subjects, especially if there is late onset in the family. Screening may not be necessary annually, but at least one colonoscopy to the caecum should be performed as polyps may only be present more proximally. Multiple biopsies may be another way to show evidence of FAP (microadenomata), but this will add to the risk of the procedure and a negative result may still not allow total reassurance. We would certainly recommend ophthalmic and dental screening as in our experience over $80 \%$ of affected patients manifest retinal changes, or dental features, or both. It is important for current risk estimation with a negative bowel test that a more accurate incidence curve is compiled. ${ }^{2}$ This may mean combining data from many centres of subjects who are shown on at least one occasion at the start of regular screening not to have polyps. In the meantime more prolonged screening beyond 30 years will be required in a number of at risk individuals.

\footnotetext{
1 Nishisho I, Nakamura Y, Miyoshi Y, Miki Y, Ando H, Hori $A$, et al. Mutations of chromosome $5 \mathrm{q} 21$ genes in FAP and colorectal cancer patients. Science 1991; 253: 665-9.

2 Burn J, Chapman P, Delhanty J, Wood C, Lalloo F, CachonGonzales MB, et al. The UK Northern Region genetic register for familial adenomatous polyposis coli: use of age of onset, congenital hypertrophy of the retinal pigment epithelium, and DNA markers in risk calculation. $₹ \mathrm{Med}$ Genet
} 1991; 28: 289-96. 
3 Jagelman DG. Clinical management of familial adenomatous polyposis. Cancer Surv 1989; 8: 159-67.

4 Murday V, Slack J. Inherited disorders associated with colorectal cancer. Cancer Surv 1989; 8: 139-57.

5 Sambrook J, Fritch EF, Maniatis T. Molecular cloning: A laboratory manual. New York: Cold Spring Harbour University Press, 1989.

6 Spirio L. A CA repeat $30-70 \mathrm{~kb}$ downstream from the adenomatous polyposis APC gene. Nucleic Acids Res 1992; 19: 6348 .

7 Groden J, Thliveris A, Samowitz W, Carlson M, Gelbert L, Albertsen $\mathrm{H}$, et al. Identification and characterisation of the Albertsen H, et al. Identification and characterisation of the familial

8 Joslyn G, Carlson M, Thliveris A, Albertsen H, Gelbert L Samowitz W, et al. Identification of deletion mutations and three new genes at the familial polyposis locus. Cell 1991; 66: 601-13.

9 Koorey DJ, McCaughen GW, Trent RJ, Gallagher ND. Risk estimation in familial adenomatous polyposis using DNA probes linked to the familial adenomatous polyposis gene. Gut 1992; 33: 530-4.

10 Pierce ER. Some genetic aspects of familial multiple polyposis of the colon in a kindred of 1422 members. Dis Colon Rectum 1968; 11 : 321-9.
11 Vasen HFA, Griffioen G, Offerhaus GJA, Den Hartog Jager FCA, Van Leeuwen-Cornelisse ISJ, Meera Khan P, et al. The value of screening and central registration of families with familial adenomatous polyposis. Dis Colon Rectum 1990; 33: 227-30.

12 Burkitt DP. Related disease - related cause. Lancet 1969; ii: 1229-31.

13 Nelson RL, Orsay CP, Pearl RK, Abcarian H. The protean manifestations of familial polyposis coli. Dis Colon Rectum 1988; 31: 699-703.

14 Leppert M, Burt R, Hughes JP, Samowitz W, Nakamura Y, Woodward $S$, et al. Genetic analysis of an inherited predisposition to colon cancer in a family with a variable number of position to colon cancer in a family with a variable number
adenomatous polyps. $N$ Engl $₹$ Med 1990; 322: 904-8.

15 Kinzler KW, Nilbert MC, Su L-K, Vogelstein B, Bryan TM, Levy DB, et al. Identification of FAP locus genes from chromosome 5q21. Science 1991; 253: 661-4.

16 Miyoshi Y, Ando H, Nagase H, Nishisho I, Horii A, Miki Y, et al. Germ-line mutations of the APC gene in 53 familia adenomatous polyposis patients. PNAS 1992; 89: 4452-6.

17 MacDonald F, Morton DG, Rind PM, Haydon J, Cullen R, Gibson J, et al. Predictive diagnosis of familial adenomatous polyposis with linked DNA markers: population based study. BMF 1992; 304: 869-72. 